\title{
A STUDY OF SACRAL INDEX: A BASIS FOR DETERMINATION OF SEX OF SACRUM
}

\author{
Rajapur Parashuram *1, Dakshayani K.R ${ }^{2}$, Manjunatha S.N ${ }^{3}$.
}

${ }^{* 1}$ Associate professor, Department of Anatomy, Mysore Medical College and Research Institute, Mysore, Karnataka, India.

2 Professor and HOD, Department of Anatomy, Mysore Medical College and Research Institute, Mysore, Karnataka, India.

${ }^{3}$ Associate Professor ${ }^{3}$, Department of Community Medicine, Mysore Medical College and Research Institute, Mysore, Karnataka, India.

\section{ABSTRACT}

Introduction: Sacrum is an important bone for identification of sex in human skeletal system, because the bones of the body are the lasts to perish after death, next to the enamel of teeth. For sex determination of human skeletal remains, sacrum always captured the attention of forensic science experts and anthropologists. Sex determination of a skeleton is a problem of concern to Paleoanthropologists, Paledemographers and Anatomists.

Materials and Methods: The present study was conducted on 100 fully ossified adult human sacra of known sex ( 50 male and 50 female), obtained from department of Anatomy, Mysore medical college and research institute, Mysore. Damaged, mutilated, deformed and anomalous sacra were excluded from the study. Sacral index was measured by measuring the length and breadth of individual sacrum with the help of sliding vernier callipers. Observations and Results: The mean maximum length of the sacrum was greater in males (102.68 $\mathrm{mm}$ ) than in females $(91.11 \mathrm{~mm})$, and this difference was found statistically significant. But the difference was not significant for mean maximum sacral breadth in male $(103.80 \mathrm{~mm})$ and in female $(105.57 \mathrm{~mm})$. Mean sacral index in females was greater $(116.18 \%)$ as compared to that in males $(101.26 \%)$ and this difference was found statistically significant.

Conclusion: The present study showed a significant difference among the average male \& female sacral indexes and considers sacral index as a valuable parameter in identification of sex. The male \& female sacra are classified under (Dolichohieric \& Hyplatyhieric) and Platyhieric group respectively. Hence, it can be concluded that sacral index is a reliable criterion for differention between sexes of sacrum that is useful for Anatomists, Anthropologists \& Forensic experts.

KEY WORDS: Sacrum, Sacral Index, Sex Determination.

Address for Correspondence: Dr. Rajapur Parashuram, Mysore Medical College and Research Institute, Mysore, Karnataka, India. E-Mail: drparashuram100@yahoo.com

Access this Article online

Quick Response code

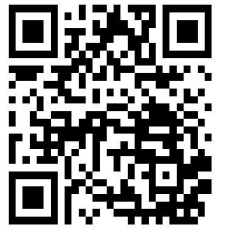

DOI: $10.16965 /$ ijar.2018.365

Journal Information

International Journal of Anatomy and Research

ICV for 2016 ISSN (E) 2321-4287 | ISSN (P) 2321-8967

90.30

https://www.ijmhr.org/ijar.htm

DOI-Prefix: https://dx.doi.org/10.16965/ijar

Article Information

Received: 23 Aug 2018

Peer Review: 24 Aug 2018

Revised: None
Accepted: 03 Oct 2018

Published (O): 05 Nov 2018

Published (P): 05 Nov 2018

\section{INTRODUCTION}

Sacrum is an important bone for identification of sex in human skeletal system, because the bones of the body are the lasts to perish after death, next to the enamel of teeth. For sex determination of human skeletal remains, sacrum always captured the attention of forensic science experts and anthropologists[1]. Sex determination of a skeleton is a problem of 
concern to paleoanthropologists, pale demographers and Anatomists.

Accuracy of sex identification based on the study by Krogman[2]: Entire skeleton is $100 \%$, pelvis plus skull is $98 \%$, pelvis alone $95 \%$, skull alone $90 \%$ and long bones alone $80 \%$. Most anatomists do not claim $100 \%$ accuracy even where skeleton is available.

The sacrum displaces metrical sexual differences. Female sacra are less curved, the curvature being most marked between the first and second segments and third and fifth, with an intervening flatter region. Male sacra are more evenly curved, relatively long and narrow and more often exceeding five segments. Average values of sacral index for male and female are $105 \%$ and $115 \%$ respectively[1].

The most important criteria for sex determination using sacrum are sacral index. There are wide variation exists between the male and female sacrum in different races and regions, and there is scarcity of data available. Thus the present study is carried out to determine the sex of sacrum using sacral index.

Objectives: To measure and record morphometry of sacrum under the following headings in order to study the sacral index which will be useful for determination of sex of sacrum.

1) Maximum length of sacrum. 2) Maximum breadth at base of sacrum. 3) Sacral index.

\section{MATERIALS AND METHODS}

Source of data: The present study was conducted on 100 fully ossified adult human sacra of known sex (50 male and 50 female), obtained from department of Anatomy, Mysore medical college and research institute, Mysore. Damaged, mutilated, deformed and anomalous sacra were excluded from the study. Sacral index was measured by measuring the length and breadth of individual sacrum with the help of sliding vernier callipers.

Study design: It is an observational study.

Type of analysis: It is a descriptive type of analysis.

\section{Measurement of parameters}

1) The length (fig-1) was measured between midpoints on the anterior margins of the prom- ontory and apex.

2) The breadth (fig-2) was measured between most anterior points on the auricular surfaces.

3) Sacral index (compares sacral breadth with sacral length) $=$ Maximum breadth $\times 100 /$ Maximum length.

The readings were recorded, tabulated and subjected for statistical analysis.

Fig. 1: Measurement of Length of sacrum.

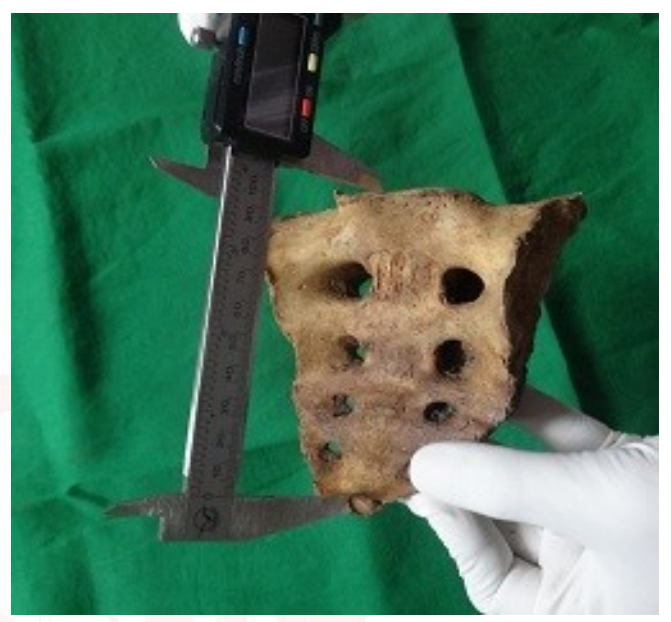

Fig 2: Measurement of Breadth of sacrum.



\section{OBSERVATIONS AND RESULTS}

The mean maximum length of the sacrum was greater in males $(102.68 \mathrm{~mm})$ than in females $(91.11 \mathrm{~mm})$, and this difference was found statistically significant. But the difference was not significant for mean maximum sacral breadth in male $(103.80 \mathrm{~mm})$ and in female $(105.57 \mathrm{~mm})$. Mean sacral index in females was greater (116.18\%) as compared to that in males (101.26\%) and this difference was found statistically significant (Table-1).

In the present study, by calculating sacral index of sacrum, 42 (84\%) males and 26 (52\%) female sacrum were identified accurately. 
Table 1: Measurements of sacrum in the present study.

\begin{tabular}{|c|c|c|c|c|c|c|c|}
\hline SI.no & Parameters & Sex & Range & Mean & SD & T-value & P-valve \\
\hline \multirow{2}{*}{1} & \multirow{2}{*}{$\begin{array}{l}\text { Length of sacrum } \\
\qquad(\mathrm{mm})\end{array}$} & Male & $89.93-120.13$ & 102.68 & 6.8 & \multirow{2}{*}{8.65} & \multirow{2}{*}{$<0.001$} \\
\hline & & Female & $75.77-103.78$ & 91.11 & 6.56 & & \\
\hline \multirow{2}{*}{2} & \multirow{2}{*}{$\begin{array}{l}\text { Breadth of } \\
\text { sacrum }(\mathrm{mm})\end{array}$} & Male & $88.55-124.61$ & 103.8 & 6.91 & \multirow{2}{*}{1.33} & \multirow{2}{*}{$>0.05$} \\
\hline & & Female & $92.03-118.45$ & 105.57 & 6.35 & & \\
\hline \multirow{2}{*}{3} & \multirow{2}{*}{ Sacral Index (\%) } & Male & $81.23-109.61$ & 101.26 & 6.04 & \multirow{2}{*}{11.03} & \multirow{2}{*}{$<0.001$} \\
\hline & & Female & $105.32-134.79$ & 116.18 & 7.4 & & \\
\hline
\end{tabular}

Table 2: Comparative study of Sacral Index with previous studies.

\begin{tabular}{|c|c|c|c|c|c|c|c|}
\hline \multirow{2}{*}{ SI. no } & \multirow{2}{*}{ Investigators } & \multicolumn{3}{|c|}{ Male sacrum } & \multicolumn{3}{|c|}{ Female sacrum } \\
\hline & & No & Mean SI & Range & No & Mean SI & Range \\
\hline 1 & Singh et.al & 26 & 94.32 & $76.3-110.94$ & 12 & 104.81 & $95.77-113.85$ \\
\hline 2 & Dapate SS & 117 & 94.58 & $77.27-118.42$ & 83 & 104.27 & $85-136.36$ \\
\hline 3 & Mishra SR et.al & 74 & 98.21 & $90-108$ & 42 & 117.84 & $103-131.25$ \\
\hline 4 & Patel MM et.al & 32 & 96.25 & 90.5-106 & 32 & 113.25 & $104.8-131$ \\
\hline 5 & Shilaja & 190 & 94.24 & $53.57-152$ & 64 & 113.19 & $91.89-146.15$ \\
\hline 6 & Raju PB et.al & 33 & 100.85 & $74.72-126.9$ & 11 & 111.39 & $88.38-134.4$ \\
\hline 7 & Mazumdar S & 127 & 94.9 & $80.5-109.3$ & 123 & 109.8 & 87.9-131.7 \\
\hline 8 & Ravichandran & 63 & 96.32 & $80.7-106.4$ & 60 & 102.29 & $93.1-108.8$ \\
\hline 9 & Poornima J et.al & 81 & 104.08 & $81-136$ & 64 & 115.72 & $85-146$ \\
\hline 10 & Mamatha Het.al & 25 & 115.92 & - & 25 & 125.2 & - \\
\hline 11 & Asthana S et.al & 58 & 96.25 & $85-106$ & 42 & 113.33 & $100-126$ \\
\hline 12 & Present study & 50 & 101.26 & $81.23-109.61$ & 50 & 116.18 & $105.32-134.79$ \\
\hline
\end{tabular}

Table 3: Comparison of Sacral Index with other races \& regions.

\begin{tabular}{|c|c|c|c|c|c|c|c|c|c|}
\hline $\begin{array}{c}\text { Sl. } \\
\text { no }\end{array}$ & Authors & Race and Regions & No & $\begin{array}{c}\text { Max-Length- } \\
\text { male }(\mathrm{mm})\end{array}$ & $\begin{array}{c}\text { Max-Length- } \\
\text { female }(\mathrm{mm})\end{array}$ & $\begin{array}{c}\text { Max-Breadth- } \\
\text { male }(\mathrm{mm})\end{array}$ & $\begin{array}{c}\text { Max-Breadth- } \\
\text { female (mm) }\end{array}$ & $\begin{array}{c}\text { Mean Sacral } \\
\text { Index- male (\%) }\end{array}$ & $\begin{array}{c}\text { Mean Sacral Index- } \\
\text { female (\%) }\end{array}$ \\
\hline 1 & Davivongs V & Australian aborigine & 50 & 96.52 & 88.12 & 99.92 & 101.24 & 104.16 & 115.4 \\
\hline 2 & Flander & American White & 50 & 110.2 & 109.64 & 116.42 & 117.62 & 106.49 & 108.59 \\
\hline 3 & Flander & American Black & 50 & 105.5 & 99.98 & 11.14 & 111.36 & 106.49 & 112.85 \\
\hline 4 & Mishra SR et. al & Indians (Agra) & 116 & 107.53 & 90.58 & 105.34 & 105.79 & 98.21 & 117.84 \\
\hline 5 & Patel MM et. al & Indians (Gujarat) & 64 & - & - & - & - & 96.25 & 113.25 \\
\hline 6 & Kataria et.al & Indians (Rajasthan) & 74 & 106.7 & 91.91 & 110.3 & 109.88 & 104.11 & 120.01 \\
\hline 7 & Bindra GS \& Mohan A & Indians (Haryana) & 60 & 106.85 & 90.89 & 108.24 & 106.87 & 101.3 & 117.56 \\
\hline 8 & Ravichandran et al & Indians (TN \& AP) & 123 & - & - & - & - & 96.32 & 102.92 \\
\hline 9 & Arora AK et. al & Indians (Punjab) & 40 & - & - & - & - & 93.68 & 125.35 \\
\hline 10 & Present study & Indians (Karnataka) & 100 & 120.13 & 103.78 & 124.61 & 118.45 & 101.26 & 116.18 \\
\hline
\end{tabular}

Table 4: Classification of sacrum by Sacral Index.

\begin{tabular}{|c|c|c|c|}
\hline Classification & $\begin{array}{c}\text { Range of sacral } \\
\text { Index (\%) }\end{array}$ & $\begin{array}{c}\text { No. of Male } \\
\text { sacrum (50) }\end{array}$ & $\begin{array}{c}\text { No. of Female } \\
\text { sacrum (50) }\end{array}$ \\
\hline Dolichohieric (narrow) & $<99.9$ & 12 & - \\
\hline Hyplatyhieric (medium) & $100-105.6$ & 29 & 3 \\
\hline Platyhieric (broad) & $>106$ & 9 & 47 \\
\hline
\end{tabular}

\section{DISCUSSION}

Human sacrum is one of the important bones used for identification of gender. The sacrum has always attracted the attention of the medicolegal experts for establishing the sex, because of its contribution to pelvic girdle and associated functional gender differences. Sex determination is necessary to make age, ancestry and stature estimations, as the sex's age differently, exhibit some degree of variation in ancestry related morphology and generally differ in height[3]. A comparison between the males and females showed that the mean length of the male sacra was found to be higher than that of the female sacra in the present study. The mean length (table-1) of the male sacra, in the present study is $102.68 \mathrm{~mm}$, which is lower when 
compared to that of Agra region (107.53 mm) studied by Mishra SR[4].et al, and the Varanasi region (104.96 mm) studied by Raju PB[5] et al.

The mean length of the female sacra $91.11 \mathrm{~mm}$ is also shorter when compared to Agra \& Varanasi regions. Comas \& Charles[6] reported a wide variation between the male and female in the Chinese, Negroes \& Bushmen. Davivongs V[7] in his study of Australian aboriginal sacra has reported mean length of sacrum to be 96.52 $\mathrm{mm} \& 88.12 \mathrm{~mm}$ in the male \& female respectively, which is lower when compared to the present study. The mean breadth (Table-1) of the male sacra in the present study is 103.80 $\mathrm{mm}$ which is close to similar observation made by Mishra SR[4] et al in the Agra region (105.34 $\mathrm{mm})$ \& Raju PB[5] et al. in the Varanasi region $(105.33 \mathrm{~mm})$ respectively. However, the mean breadth, in the present study in females showed a similar value $(105.57 \mathrm{~mm})$ than that of Agra (105.79 $\mathrm{mm})$ \& Varanasi regions $(103 \mathrm{~mm})$. In the Australian aboriginal females, the maximum breadth of sacrum was $101.24 \mathrm{~mm}$, which is higher than that of males $(99.92 \mathrm{~mm})$ of the same race studied by Davivongs V[7]. Thus there exists a regional and racial difference in the length $\&$ breadth of the sacrum.

Based on the sacral index, Anthropologists have classified the sacra into the followings groups: 1) Dolichohieric (narrow sacrum with $\mathrm{SI}<99.9$ ), 2) Hyplatyhieric (medium sacrum with $\mathrm{SI}$ 100-105.9) \& 3) Platyhieric (broad with SI >106). The mean sacral indexes (table-1) of the male \& female sacra in the present study are $101.26 \%$ \& $116.18 \%$ respectively which falls under Hyplatyhieric \& Platyhieric groups respectively. Almost similar observations were reported by Poornima J[8] et.al (male: $104.08 \%$ \& female: 115.72\%), Asthana S et.al (male: 96.25 \& female: 113.33), Raju PB et.al and Davivongs V. Mishra SR et al, in his study has classified the male sacra (SI: $98.22 \%$ ) under Dolichochieric group and female sacra (SI: $117.84 \%)$ under Platyhieric group which is almost similar to the present study. The mean sacral index reported by Mamatha $\mathrm{H}[9]$.et al in male and female was $115.92 \%$ \& $125.2 \%$ respectively, which was higher when compared to present study. The mean sacral index reported by Patel MM[10] et.al in male and female was 96.25 \& 113.25 respectively. The average sacral index for British males[11] is 112 and for females is 116 . Indexes above 100 class the sacra as Platyhieric, those with indexes below 100 being Dolichohieric. The gorilla gives a sacral index of 72 .

Present study showed that according to sacral index method, $84 \%$ (42) of male sacra were identified, and $52 \%$ (26) of female sacra were identified accurately. Patel MM[10] et al. also showed that $62.5 \%$ of male sacra and $68.75 \%$ of female sacra were identified using sacral index method. Bindra GS \& Mohan A[12] also showed that $66.6 \%$ of male sacra and $70 \%$ of female sacra were identified using sacral index method.

\section{CONCLUSION}

The present study showed a significant difference among the average male $\&$ female sacral indexes and considers sacral index as a valuable parameter in identification of sex. The male \& female sacra are classified under (Dolichohieric \& Hyplatyhieric) and Platyhieric group respectively. Hence, it can be concluded that sacral index is a reliable criterion for differention between sexes of sacrum that is useful for Anatomists.

\section{Conflicts of Interests: None}

\section{REFERENCES}

[1]. Standring S. Gray's Anatomy: The Anatomical Basis of Clinical Practice, $41^{\text {st }} \mathrm{Ed}$, Churchill Livingstone Elsevier, London, 2016; P: 1348.

[2]. Narayan Reddy KS, Murty OP. The Essentials of Forensic Medicine and Toxicology, $34^{\text {th }}$ Ed, Jaypee brothers medical publishers, New Delhi, 2017; P: 63.

[3]. Stewart TD. Hrdlicka's Practical Anthropometry, $4^{\text {th }}$ Ed, Wistar Institute of Anatomy and Biology, Philadelphia, 1952; P: 127-132.

[4]. Mishra SR, Singh PJ, Agarwal AK, Gupta RN. Identification of sex of sacrum of Agra region. J Anat. Soc. India. 2003; 52(2):132-136.

[5]. Raju PB, Singh S, Padmanabhan R. Sex determination and sacrum. J Anat Soc India 1980; 30 (1): 1315.

[6]. Comas J, Charles C. Manual of physical anthropology 1961, Thomas Springfield, Illinois, USA, 1961; P: 415-416.

[7]. Davivongs V. The pelvic girdle of the Australian aborigines- sex differences and sex determination. Am J Phys Anthrop 1963; 21: 443-445. 
[8]. Poornima J, Jyothinath K, Shamsunder Rao V. Study of sacral index: Comparison between different regional populations of India and abroad. Int J Anat Res 2014; 2(4):640-644.

[9]. Mamatha $\mathrm{H}$ et al. Significance of various sacral measurements in the determination of sex in south Indian population. Int J Cur Res Rev, Oct 2012; 4(20): 112-118

[10]. Patel MM, Gupta BD, Singel TC. Sexing of sacrum by sacral index and kimura's base-wing index. JIAFM 2005; 27 (1): 5-9
[11]. Ernest J Frazer. The Anatomy of the human skeleton, $4^{\text {th }}$ Ed, J and A Churchill Itd, London, 1948; P: 36.

[12]. Bindra GS, Mohan A. Sacral index: Application in sex determination of sacrum. Int J Sci Stud 2015; 2 (10): 79-81.

How to cite this article:

Rajapur Parashuram, Dakshayani K.R, Manjunatha S.N. A STUDY OF SACRAL INDEX: A BASIS FOR DETERMINATION OF SEX OF SACRUM. Int J Anat Res 2018;6(4.2):5873-5877. DOI: 10.16965/ ijar.2018.365 